\title{
Pepsin 1 secretion in chronic peptic ulceration
}

\author{
V WALKER* AND W H TAYLOR \\ From the Department of Chemical Pathology, Liverpool Area Health Authority (T), Liverpool
}

SUMMARY In patients with peptic ulceration, both vagal stimulation by insulin hypoglycaemia and stimulation by pentagastrin cause pepsin 1 to be secreted into gastric juice. There is a secretory threshold for pepsin 1, below which only pepsins 3 and 5 are secreted. Pepsin 1 accounts for an increasing proportion of the total peptic activity $/ \mathrm{ml}$ of gastric juice as the total activity increases. Higher concentrations of pepsin 1 in the basal gastric secretion occurred significantly more frequently in patients with duodenal ulcer than with gastric ulcer. In these patients there may be an increased 'background' secretory drive.

On agar gel electrophoresis of normal human gastric juice at ph 5.0, up to eight zones of proteolytic activity may be recognised, at least five of which represent unique pepsins. ${ }^{1}$ Using the nomenclature suggested by these authors, ${ }^{2}$ the pepsins are numbered $1,2,3 \mathrm{a}, 3$, and 5 in order of electrophoretic mobility to the anode with reference to a porcine pepsin marker. Pepsin 3 is always the most abundant of the pepsins present, usually followed by pepsin 5 . The proportional contribution made by pepsin 1 to the total peptic activity is variable.

Taylor $^{3}$ found that in response to histamine, patients with chronic peptic ulceration secreted pepsin 1 significantly more often and in greater quantity than did control subjects. Vagally stimulated gastric secretions were not studied. In the cat, prolonged electrical stimulation of the vagi results in the secretion of increasing amounts of the most electronegative pepsin, 'cat pepsin 1'. ${ }^{4}$ This observation prompted further study of pepsin 1 secretion by patients with chronic peptic ulceration, both in response to vagal stimulation by insulin hypoglycaemia and to pentagastrin.

\section{Methods}

PATIENTS

Thirty-three patients were studied who were under the care of Dr J H Baron (Hammersmith Hospital, London) or $\operatorname{Dr}$ R B McConnell (Broadgreen Hospital, Liverpool). All had peptic ulceration

*Address for correspondence; Dr V Walker, Department of Chemical Pathology, Southampton General Hospital, Tremona Road, Southampton SO9 4XY.

Received for publication 20 March 1980 confirmed radiologically and/or by gastroscopy, and underwent gastric acid output tests during their pre-treatment assessment.

Gastric juice was obtained via nasogastric tube. The resting (overnight) secretion was aspirated, and the basal secretions collected in 15 minute aliquots using continuous pump suction for 60 minutes (Hammersmith) or 45 minutes (Broadgreen). Twentyfive patients (12 with duodenal ulcer, 13 with gastric ulcer) then received pentagastrin by intramuscular or subcutaneous injection $(6 \mu \mathrm{g} / \mathrm{kg}$ body weight) and the stimulated gastric secretion was collected for 60 minutes or 90 minutes. The remaining eight patients (six with duodenal ulcer; two with gastric ulcer) were given instead $0 \cdot 15$ units soluble insulin intravenously, and the stimulated secretion was collected for 90 minutes (seven patients) or 120 minutes (one patient). In each case, the blood glucose fell below $2 \cdot 2 \mathrm{mmol} / \mathrm{l}$. One other patient was studied four months after successful complete vagotomy for duodenal ulcer. After basal collections, gastric juice was collected for 90 minutes after intravenous insulin, $0 \cdot 15$ units $/ \mathrm{kg}$ body weight, and for a further 60 minutes after subcutaneous pentagastrin $(6 \mu \mathrm{g} / \mathrm{kg})$.

Gastric juice was transported to the laboratory in ice/water and kept at $0-4^{\circ}$ until it was assayed, within 48 hours of collection.

\section{TECHNIQUES}

\section{Determination of proteolytic activity}

The total peptic activity of the gastric juice samples was determined at $\mathrm{pH} 2 \cdot 0$, using the method of Anson and Mirsky ${ }^{5}$ as modified by Hanley et al. ${ }^{6}$ and further by Etherington and Taylor. ${ }^{1}$ Solutions of crystalline porcine pepsin (Sigma Chemical Co 
Ltd, St. Louis, USA) of increasing concentration were analysed similarly. By reference to the proteolytic activity curve obtained, the activities of human gastric juice samples could therefore be expressed in terms of $\mu \mathrm{g}$ porcine pepsin equivalent.

\section{Agar gel electrophoresis and semi-quantification of pepsin 1}

As fully quantitative methods are not yet available for the determination of the individual pepsins in the presence of each other, the enzyme concentrations are measured semi-quantitatively from agar gel electrophoretograms as described by Walker and Taylor ${ }^{7}$ and Waft, Roberts and Taylor. ${ }^{8}$ Each pepsin was assigned a grade of 0 , for no activity, to ++++ for maximal activity. By comparison with electrophoretograms of known amounts of porcine pepsin, grade ++++ is approximately equivalent to $750 \mu \mathrm{g}$ of porcine pepsin per $\mathrm{ml}$ of undiluted gastric juice and grades,,++++++ , and 'trace' to $250,60,22 \cdot 5$, and $10.5 \mu \mathrm{g} / \mathrm{ml}$ respectively. Grading was by two observers, one of whom knew nothing of the details of the individual patients or of their gastric secretions. In instances of uncertainty the intermediate grades $+(+)$ and $++(+)$ were sometimes used.

\section{Results}

BASAL AND STIMULATED PEPSIN 1 SECRETION Basal conditions

Under basal conditions (Table 1) the gastric secretions of eight of the 33 patients, three with gastric ulcer, five with duodenal ulcer, were of neutral $\mathrm{pH}$ and no peptic activity was detected. In two patients with gastric ulcer, electrophoresis was not carried out, so that quantification of pepsin 1 was not possible. Three patients whose secretions were acid secreted pepsin 1 in only trace amounts. Although the mean total pepsin concentration of the gastric juice of patients with duodenal ulcer was not significantly higher than that of patients with gastric ulcer $(P>0 \cdot 3)$, significantly more patients with duodenal ulcer (eight of 13 whose basal secretion was acid) secreted pepsin 1 in amounts graded ++ than did comparable patients with gastric ulcer (1 of 10) $(0.02<\mathrm{P}<0.05)$. No patient secreted a high concentration of pepsin $1(+++$ or more $)$.

\section{Vagal stimulation by insulin hypoglycaemia}

In response to this stimulation all eight patients studied secreted pepsin 1 in greater than trace amounts. Four patients, who all had duodenal ulceration, secreted a high concentration $(+++$ or more). When all patients with peptic ulceration are considered together, significantly more patients secreted ++ or more after insulin than basally $(P<0.01)$, but when only patients with duodenal ulcer are considered (whether including all 18 basal observations or only those of the six insulin stimulated patients) the difference is no longer significant $(P>0.05)$. The mean concentration of total pepsin secreted by patients with duodenal ulcer was significantly higher after insulin than in the basal state $(\mathrm{P}<0.001)$. A similar comparison is not meaningful for patients with gastric ulcer (only two had insulin tests).

Electrophoretograms of one patient with duodenal ulcer are shown in Fig. 1. The total peptic activity of the first 15 minute sample after insulin was $730 \mu \mathrm{g} / \mathrm{ml}$ (porcine pepsin equivalent) to which pepsin 1 made a negligible contribution. With the onset of hypoglycaemia, the total peptic activity increased to $4050 \mu \mathrm{g} / \mathrm{ml}$ in sample 2 , and a striking increase in pepsin 1 secretion occurred.

\section{Pentagastrin administration}

After pentagastrin administration the secretory response with respect to pepsin 1 and total pepsin concentrations was similar among patients with gastric ulcer to that among patients with duodenal ulcer. Twenty-four of the 25 patients secreted more than trace amounts of pepsin 1 . The incidence of patients with duodenal ulcer secreting ++ or more pepsin 1 was not significantly different from that under basal conditions $(P>0 \cdot 20)$ or after insulin

Table 1 Pepsin 1 secretion by patients with peptic ulcer

\begin{tabular}{|c|c|c|c|c|c|c|}
\hline \multirow[b]{2}{*}{ Stimulant } & \multirow[b]{2}{*}{ Patients (no.) } & \multicolumn{4}{|c|}{ Pepsin 1 (nos. with) } & \multirow{2}{*}{$\begin{array}{l}\text { Total pepsin concentration* }(\mu \mathrm{g} / \mathrm{ml}) \\
\text { Mean }(\text { range) }\end{array}$} \\
\hline & & 'Trace' & + & ++ & +++ & \\
\hline \multirow[t]{2}{*}{ Basal } & Duodenal ulcer (18) & 1 & 4 & 8 & 0 & $596(0-1210)$ \\
\hline & Gastric ulcer† (13) & 2 & 7 & 1 & 0 & $469(0-1100)$ \\
\hline \multirow[t]{2}{*}{ Insulin } & DU (6) & 0 & 0 & 2 & 4 & $2290(1705-4200)$ \\
\hline & GU (2) & 0 & 1 & 1 & 0 & $1500(1480 ; 1505)$ \\
\hline \multirow{2}{*}{ Pentagastrin } & DU (12) & 1 & 2 & 6 & 3 & $1160(595-2040)$ \\
\hline & GU (13) & 0 & 4 & 6 & 3 & $980(640-1350)$ \\
\hline
\end{tabular}

*For insulin and pentagastrin stimulation, total pepsin concentration was the highest observed in any 15 minute period in each patient. Tota pepsin concentration under basal conditions was the mean of all the 15 minute basal gastric juice collections from each patient. The pepsin 1 grades are the highest observed for each patient for each stimulant.

†Two patients with gastric ulcer whose basal pepsin 1 secretion was not determined have been excluded. 


\section{Pepsin 1}

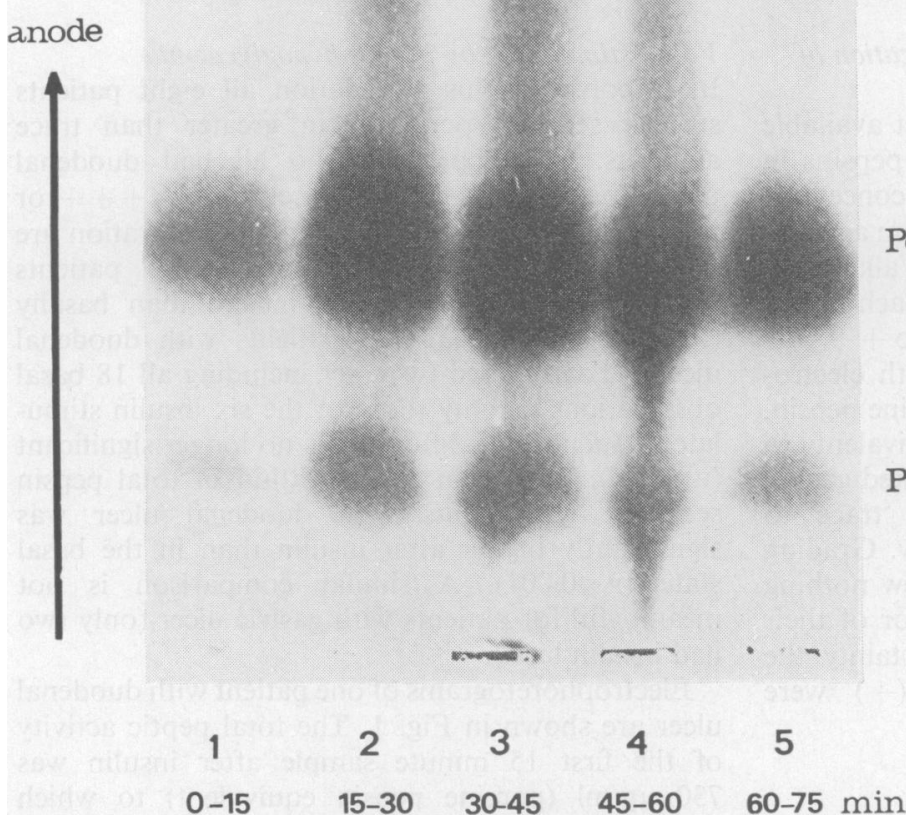

hypoglycaemia $(P>0 \cdot 50)$. Of the 10 patients whose basal secretions were acid, six secreted ++ of pepsin 1 basally and eight of them secreted ++ or more in response to pentagastrin. On the other hand, significantly more patients with gastric ulcer secreted ++ or more pepsin 1 in response to pentagastrin than basally $(P<0.001)$. Of the nine patients whose basal secretions were acid, one secreted ++ basally and six secreted ++ after pentagastrin. Three patients with gastric ulcer and three with duodenal ulcer secreted high concentrations of pepsin $1(+++$ or more $)$.

Pepsin 1 secretion after complete vagotomy

One patient was studied opportunistically who had undergone vagotomy and gastroenterostomy four months before a combined insulin/pentagastrin test. He was asymptomatic, and vagal section was complete according to the criteria of Bank et al. ${ }^{9}$ Pepsin 1 was secreted basally, in consecutive 15 minute periods, in amounts graded,+++ and + ; after insulin in amounts graded $\mathbf{0 , 0},+,+(+)$, and $\mathbf{0}$; and after pentagastrin in amounts graded ++ , ,+++ , and + .

Table 2 Total pepsin concentrations (mean $\pm 1 S E M$ ) of gastric juice 15 minute samples, graded according to pepsin 1 content

\begin{tabular}{|c|c|c|c|c|c|c|}
\hline \multirow{3}{*}{$\begin{array}{l}\text { Pepsin } 1 \text { concn. } \\
(\mu g / m l)\end{array}$} & \multicolumn{3}{|l|}{ Duodenal ulcer } & \multicolumn{3}{|l|}{ Gastric ulcer } \\
\hline & \multicolumn{3}{|c|}{$\overline{\text { Total pepsin concentration }(\mu \mathrm{g} / \mathrm{ml} ; \text { mean } \pm 1 \text { SEM) }}$} & \multicolumn{3}{|c|}{ Total pepsin concentration $(\mu \mathrm{g} / \mathrm{ml} ;$ mean \pm 1 SEM) } \\
\hline & Basal & Post-pentagastrin & Post-insulin & Basal & Post-pentagastrin & Post-insulin \\
\hline 0 & $\begin{array}{l}105 \text { (one sample } \\
\text { only) }\end{array}$ & & $\begin{array}{l}310 \pm 152 \\
(5 \text { samples) }\end{array}$ & $\begin{array}{l}310 \pm 117 \\
\text { (4 samples) }\end{array}$ & & \\
\hline Trace $(10 \cdot 5)$ & $460 \pm 71$ & $615 \pm 29$ & & $617 \pm 91$ & $580 \pm 9$ & $\begin{array}{l}350(260 ; 440) \\
\text { (2 samples) }\end{array}$ \\
\hline $\begin{array}{l}+(22 \cdot 5) \\
+(+)(36 \cdot 8)\end{array}$ & $795 \pm 51$ & $930 \pm 50$ & $\begin{array}{l}1098 \pm 145 \\
1370 \pm 222\end{array}$ & $680 \pm 51$ & $663 \pm 23$ & $\begin{array}{l}764 \pm 89 \\
1215(930 ; 1500) \\
\text { (2 samples) }\end{array}$ \\
\hline $\begin{array}{l}++(60 \cdot 0) \\
++(+)(122.6) \\
+++(250 \cdot 5)\end{array}$ & $1035 \pm 36$ & $\begin{array}{c}950 \pm 66 \\
1515 \pm 246\end{array}$ & $\begin{array}{l}1550 \pm 113 \\
1850 \pm 103 \\
3060 \pm 550\end{array}$ & & $\begin{array}{r}920 \pm 32 \\
1080 \pm 80\end{array}$ & 1480 (1 sample) \\
\hline
\end{tabular}




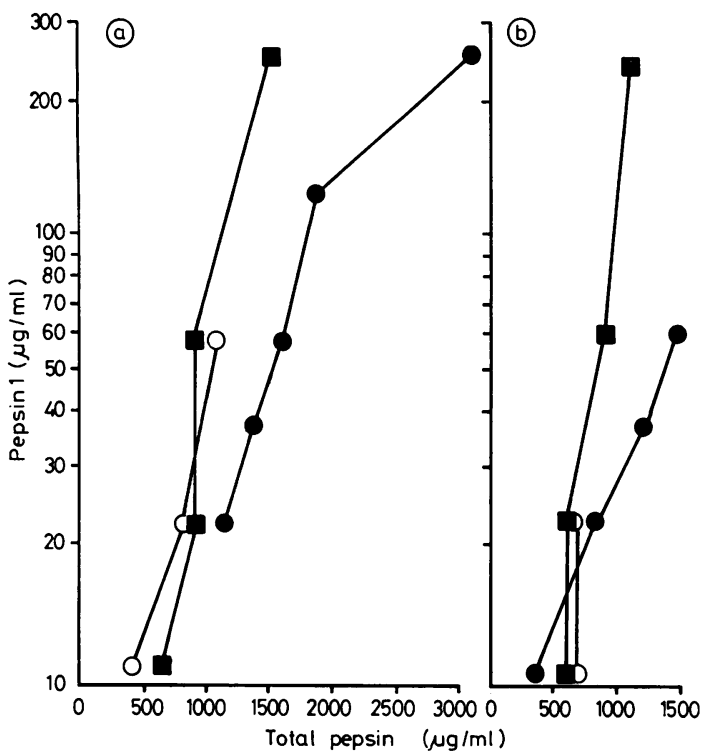

Fig. 2 The relationship between pepsin 1 grade and mean total peptic activity/ml of the basal, pentagastrin-, and insulin-stimulated gastric secretion of patients with (a) duodenal and (b) gastric ulcer. $\bigcirc-\bigcirc$ basal; - after pentagastrin; - -1 after insulin.

Total peptic activities of samples containing pepsin 1 in undetectable or in trace amounts

Five basal samples of gastric juice of acid $\mathrm{pH}$ in which pepsin 1 was undetectable - that is, less than $10.5 \mu \mathrm{g} / \mathrm{ml}$ of pepsin 1 was present-had a mean total peptic activity of $269 \mu \mathrm{g} / \mathrm{ml}$, and five similar samples collected after insulin, before the secretory response to hypoglycaemia started, had a mean total peptic activity of $310 \mu \mathrm{g} / \mathrm{ml}$ (Table 2). The mean values are lower than those observed for all samples containing trace amounts of pepsin 1 $(512 \mu \mathrm{g} / \mathrm{ml}$ under basal conditions, $603 \mu \mathrm{g} / \mathrm{ml}$ after pentagastrin, $350 \mu \mathrm{g} / \mathrm{ml}$ after insulin hypoglycaemia), although the ranges overlap.

Relationship of pepsin 1 secretion to total peptic activity of gastric juice

The results for all the 15 minute gastric juice samples collected basally or after stimulation were grouped according to the pepsin 1 grade, and the mean peptic activity $( \pm 1$ SEM) was calculated for each group (Table 2). The mean values are plotted semilogarithmically against the pepsin 1 grades, expressed as porcine pepsin equivalent (Figs. $2 \mathrm{a}$ and b); pepsin 1 concentration was also calculated as a percentage of the total pepsin concentration (Table 3). From these (approximate) representations of the relationship between pepsin 1 and total pepsin concentration, it is apparent that the proportionate contribution made by pepsin 1 to the total activity increases progressively as the total activity increases. Thus, in response to pentagastrin, samples from patients with duodenal ulcer which contain a 'trace' of pepsin 1 have a mean total peptic activity of $615 \mu \mathrm{g} / \mathrm{ml}$, approximately $1.7 \%$ being contributed by pepsin 1 . Samples with +++ of pepsin 1 on the other hand have a mean total activity which is 2.5 times higher, yet the contribution made by pepsin 1 is around $16.5 \%$. It is also apparent (Fig. 2a) that, for patients with duodenal ulcer at least, the pepsin secretory response after insulin differs from that after pentagastrin: higher total pepsin concentrations are secreted in response to insulin, yet pepsin 1 makes a smaller proportional contribution to the increase (Table 3). Of the 1215 minute samples collected after insulin from two patients with gastric ulcer, three samples, collected before the secretory response began, were of neutral $\mathrm{pH}$ and had no peptic activity. Figures for the remaining nine samples are shown in Tables 2 and 3. Although the numbers are small, the pattern is similar to that of patients with duodenal ulcer.

Table 3 Pepsin 1 as percentage of total pepsin concentration

\begin{tabular}{|c|c|c|c|c|c|c|}
\hline \multirow{3}{*}{$\begin{array}{l}\text { Pepsin } 1 \\
\text { concn. }\end{array}$} & \multicolumn{6}{|c|}{ Pepsin 1 as percentage of total pepsin concentration (mean and range) } \\
\hline & \multicolumn{3}{|c|}{ Duodenal ulcer } & \multicolumn{3}{|c|}{ Gastric ulcer } \\
\hline & Basal & Post-pentag.* & Post-insulin & Basal & Post-pentag. & Post-insulin \\
\hline Trace & $\begin{array}{l}2 \cdot 3 \\
(1 \cdot 4-4 \cdot 8)\end{array}$ & $\begin{array}{l}1 \cdot 7 \\
(1 \cdot 4-2 \cdot 0)\end{array}$ & & $\begin{array}{l}1 \cdot 7 \\
(1 \cdot 3-3 \cdot 0)\end{array}$ & $\begin{array}{l}1 \cdot 8 \\
(1 \cdot 8-1 \cdot 9)\end{array}$ & $\begin{array}{l}3 \cdot 2 \\
(2 \cdot 4 ; 4 \cdot 0)\end{array}$ \\
\hline $\begin{array}{l}+ \\
+(+)\end{array}$ & $\begin{array}{l}3 \cdot 0 \\
(2 \cdot 1-6 \cdot 6)\end{array}$ & $\begin{array}{l}2 \cdot 4 \\
(1 \cdot 8-6 \cdot 6)\end{array}$ & $\begin{array}{l}2 \cdot 1 \\
(1 \cdot 5-3 \cdot 1) \\
2 \cdot 7 \\
(2 \cdot 0-3 \cdot 8)\end{array}$ & $\begin{array}{l}3 \cdot 3 \\
(2 \cdot 0-11 \cdot 8)\end{array}$ & $\begin{array}{l}3 \cdot 4 \\
(2 \cdot 4-5 \cdot 2)\end{array}$ & $\begin{array}{l}2 \cdot 9 \\
(2 \cdot 3-3 \cdot 9) \\
3 \cdot 3 \\
(2 \cdot 5 ; 4 \cdot 0)\end{array}$ \\
\hline $\begin{array}{l}+t \\
++(+)\end{array}$ & $\begin{array}{l}5 \cdot 8 \\
(5 \cdot 2-8 \cdot 1)\end{array}$ & $\begin{array}{l}6 \cdot 3 \\
(3 \cdot 5-18 \cdot 2)\end{array}$ & $\begin{array}{l}3 \cdot 9 \\
(2 \cdot 9-6 \cdot 1) \\
6 \cdot 6 \\
(6 \cdot 3-8 \cdot 6)\end{array}$ & & $\begin{array}{l}6 \cdot 5 \\
(4 \cdot 5-10 \cdot 3)\end{array}$ & $\begin{array}{l}4 \cdot 1 \\
\text { (1 sample) }\end{array}$ \\
\hline$+t+$ & & $\begin{array}{l}16 \cdot 5 \\
(12 \cdot 2-19 \cdot 5)\end{array}$ & $\begin{array}{l}8 \cdot 2 \\
(5 \cdot 7-14 \cdot 6)\end{array}$ & & $\begin{array}{l}23 \cdot 2 \\
(20 \cdot 5-26 \cdot 9)\end{array}$ & \\
\hline
\end{tabular}

*Post-pentagastrin. 


\section{Discussion}

These observations on patients with chronic peptic ulceration reveal a number of interesting features of pepsin 1 secretion. First, it was found that at low levels of gastric stimulation-for example, in the basal state-pepsin 1 may be undetectable in gastric juice which contains both of the other two major pepsins, pepsins 3 and 5 . As pepsin 1 was detected in the gastric juice of all the subjects after gastric stimulation, all had the capacity to produce this pepsin. It may be postulated, therefore, that the threshold level of stimulation for pepsin 1 secretion is higher than that for secretions of pepsins 3 and 5 . As little as $10.5 \mu \mathrm{g} / \mathrm{ml}$ of pepsin 1 is detectable by electrophoresis, and this represented approximately $2.0 \%$ of the mean total pepsin concentration of samples containing a 'trace' of pepsin 1 (Table 3). It is unlikely, therefore, that the apparent threshold is an artefact arising from insensitivity of the method. Wright ${ }^{10}$ has previously suggested that, in the cat, certain pepsins are secreted only when stimulation exceeds a threshold level.

The vagus is known to stimulate pepsin secretion in $\operatorname{man}^{11}$ and acetylcholine was shown to stimulate pepsinogen secretion in a dose-dependent fashion by rabbit gastric mucosa in organ culture. ${ }^{12}$ In response to vagal stimulation by insulin hypoglycaemia, all the patients in the present study secreted pepsin 1, together with increased amounts of pepsins 3 and 5 . The increase in pepsin 1 concentration did not parallel the increase in total pepsin concentration, however, but had an approximately logarithmic relation to it-thus pepsin 1 accounted for proportionately more of the total peptic activity when this was high than for lower total activities. Wright et al. ${ }^{4}$ observed that prolonged electrical stimulation of the vagi in the cat resulted in the secretion of increasing amounts of the most electronegative pepsin, 'cat pepsin 1'. Thus it appears that vagal stimulation not only increases the total quantity of pepsin secreted by the gastric mucosa, but also influences the composition of the pepsin mixture released. Pentagastrin was also found to stimulate pepsin 1 secretion in patients with peptic ulceration. In the case of patients with duodenal ulcer, there was a difference in the responses to insulin and to pentagastrin: the total concentration of pepsins secreted was smaller after pentagastrin, yet the contribution made by pepsin 1 to the increase was proportionally higher. Again, this situation may be analogous to that in the cat, in which, although the total pepsin response to pentagastrin is small, 'pepsin 1' is a major contributor ${ }^{10}$ In patients with gastric ulcer, the numbers studied are too few to enable a comparison between pentagastrin and insulin stimulation to be made.

In the present investigation pepsin 1 was found when present, to account for $1.3 \%$ to $26.9 \%$ of the total peptic activity (upon globin) of the gastric juice samples (Table 3). Using a different method of assay, which does not involve agar gel electrophoresis, but which utilises the different activities of pepsins 1, 3, and 5 upon ovalbumin, Walker ${ }^{13}$ found the proportion of pepsin 1 to vary from $4.5 \%$ to $21.7 \%$ of the total peptic activity. The two differing methods thus give values in the same range.

Gastric juice samples collected under basal conditions from some patients with duodenal ulcer contained a moderately high concentration $(++)$ of pepsin 1. Under the conditions of a gastric function test, truly basal conditions are not always achieved. If an increased secretion of pepsin 1 is indicative of stimulation of the gastric mucosa, then in some patients with duodenal ulcer-(and in significantly more than patients with gastric ulcer)there was either an increased level of stimulation basally or the gastric chief cells were more sensitive to a normal level of basal stimulation. There is evidence that in some patients with duodenal ulcer there may be increased 'vagal drive' on the gastric mucosa ${ }^{14}$ Stimulation by endogenous gastrin seems a less likely possibility, as fasting serum gastrin levels in duodental ulcer lie in the lower part of the normal range when measured by radio-immunoassay. ${ }^{15}$

The question now arises as to whether pepsin 1 plays a greater aetiological role in peptic ulceration than do the other pepsins of gastric juice. Although patients with duodenal ulcer as a group have a higher total pepsin secretion than normal subjects, most investigators have found that the ranges for normal and duodenal ulcer subjects overlap. Patients with gastric ulceration usually secrete normal amounts of pepsin. Thus peptic ulceration in many individuals cannot be attributed to an increased total secretion of pepsins. Work in animals has shown that, although solutions of porcine pepsin in hydrochloric acid are considerably more ulcerogenic to jejunal mucosa than hydrochloric acid alone, the severity of ulceration does not depend closely on the concentration of pepsin applied. ${ }^{1617}$ A qualitative change in the pepsins secreted might on the other hand increase the 'peptic aggression' of gastric juice. ${ }^{18}{ }^{19}$ In some of its proteolytic actions, pepsin 1 resembles closely the predominant pepsin of gastric juice, pepsin $3^{2021}$ however, pepsin 1 digests the glycoprotein ovalbumin more readily than pepsin 3 does $^{22}$ and is more active towards collagen..$^{23}$ It is not inconceivable that pepsin 1 may augment the 'peptic aggression' of the other pepsins towards the gastric or duodenal mucosa to a significant degree in some 
circumstances. Taylor, ${ }^{3}$ using a rather less sensitive electrophoretic technique, found that $68 \%$ of patients with duodenal ulcer and $78 \%$ with gastric ulcer secreted pepsin 1 in response to histaminesignificantly higher incidences than among patients without ulceration $(47 \%)$.

Pepsin 1 has beeil observed in increased concentration in groups of individuals having an increased risk of acute or chronic ulceration: in children after cardiac surgery, and in some patients requiring intensive care after trauma,${ }^{24}$ and in non-secretors of blood group substances. ${ }^{8}$ Cigarette smokers with chronic peptic ulceration secrete more pepsin 1 as a group than non-smokers with ulcers. ${ }^{7}$ Finally, a decrease in pepsin 1 secretion was observed in patients with chronic peptic ulcer who responded well to treatment with carbenoxolone but not in those who failed to respond. ${ }^{25}$ In some of these situations the changes in pepsin 1 secretion probably reflect changes in the intensity of gastric mucosal stimulation, and in this context the enzyme may be looked upon as a sensitive 'marker' of such stimulation. Pepsin 1 may, however, make a considerable contribution to a stimulated juice; thus from Tables 2 and 3 , in gastric ulcer the difference of total pepsin concentration between the highest basal level $(680 \mu \mathrm{g} / \mathrm{ml})$ and the highest stimulated level $(1080$ $\mu \mathrm{g} / \mathrm{ml}$ ) is $400 \mu \mathrm{g} / \mathrm{ml}$, of which about $227 \mu \mathrm{g} / \mathrm{ml}$ is pepsin 1 . The possible special role of pepsin 1 in ulcerogenesis should therefore repay continuing study.

We are very grateful to $\mathrm{Dr} \mathbf{J} \mathrm{H}$ Baron and $\mathrm{Dr}$ R B McConnell for their help in providing gastric juice samples, and allowing access to clinical data of their patients.

\section{References}

${ }^{1}$ Etherington DJ, Taylor WH. The pepsins of normal human gastric juice. Biochem $J$ 1969; 113: 663-8.

${ }^{2}$ Etherington DJ, Taylor WH. Nomenclature of the pepsins. Nature 1967; 216: 279-80.

${ }^{3}$ Taylor WH. Pepsins of patients with peptic ulcer. Nature 1970; 227: 76-7.

${ }^{4}$ Wright CL, Shaw B, Sanders DJ, Reed JD. Variation in the proportions of individual pepsins secreted by the cat in response to vagal stimulation and hypoglycaemia. Clin Sci Molec Med 1975; 48: 297-305.

${ }^{5}$ Anson ML, Mirsky AE. Estimation of pepsin with haemoglobin. J Gen Physiol 1932; 16: 59-63.

${ }^{6}$ Hanley WB, Boyer SH, Naughton MA. Electrophoretic and functional heterogeneity of pepsinogen in several species. Nature 1966; 209: 996-1002.
${ }^{7}$ Walker V, Taylor WH. Cigarette smoking, chronic peptic ulceration, and pepsin 1 secretion. Gut 1979; 20: 971-6.

${ }^{8}$ Waft L, Roberts NB, Taylor WH. Hereditary aspects of duodenal ulceration: pepsin 1 secretion in relation to ABO blood groups and ABH secretor status. $J$ Med Genet 1979; 16: 423-7.

${ }^{9}$ Bank S, Marks IN, Louw JH. Histamine- and insulinstimulated gastric acid secretion after selective and truncal vagotomy. Gut $1967 ; 8: 36-41$.

${ }^{10}$ Wright CL. Pepsinogens and pepsins of the cat. University of Newcastle upon Tyne: Thesis, 1973.

${ }^{11}$ Hirschowitz BI. Secretion of pepsinogen. In: Code CF, ed. Handbook of Physiology, Section 6, Alimentary Canal Vol. II. Washington, U.S.A. American Physiological Society, 1967: 889-918.

${ }^{12}$ Kapadia CR, Donaldson RM Jr. Macromolecular secretion by isolated gastric mucosa. Fundamental differences in pepsinogen and intrinsic factor secretion. Gastroenterology 1978; 74 : 535-9

${ }^{13}$ Walker V. Aspects of the pathophysiology of the pepsins, Liverpool: MD Thesis, 1976: 146-51.

${ }^{14}$ Baron JH, Gutierrez LV, Spencer J, Tinker J, Welbourn RB. The insulin test in the unoperated subject (abstract). Gut 1969; 10: 1046-7.

${ }^{15}$ Korman MG, Soveny C, Hansky J. Serum gastrin in duodenal ulcer. Gut 1971; 12: 899-902.

${ }^{16}$ Schiffrin MJ, Warren AA. Some factors concerned in the production of experimental ulceration of the G-I tract in cats. Am J Dig Dis 1942; 9: 205-9.

${ }^{17}$ Driver RL, Chappell RH, Carmichael EB. Effect of concentration of pepsin and the differential susceptibility of jejunal segments in experimental jejunal ulcers in the dog. Am J Dig Dis 1945; 12: 166-7.

${ }^{18}$ Taylor WH. Gastric proteolysis in disease. 2. The proteolytic activity of gastric juice and gastric mucosal extracts from patients with chronic gastric and duodenal ulcer. J Clin Pathol 1959; 12: 338-43.

${ }^{19}$ Fernandez Costa J. Cambios en La Actividad Proteolitica del Jugo Gastrico Durante La Formacion de Ulcera Experimental. Thesis: University of Havana 1970.

${ }^{20}$ Roberts NB, Taylor WH. A comparison of the properties of pure human pepsins 1, 2, 3, and 5. (Abstract) Biochem J 1972; 128: 103p.

${ }^{21}$ Roberts NB, Taylor WH. Action of human pepsins 1, 2,3 , and 5 on the oxidised B-chain of insulin. Biochem $J$ 1979; 179: 183-90.

${ }^{22}$ Walker V, Taylor WH. Ovalbumin digestion by human pepsins 1, 3, and 5. Biochem J 1978; 176: 429-32.

${ }^{23}$ Etherington DJ, Roberts NB, Taylor WH. The collagen degrading activity of purified human pepsins 1 and 3 . Clin Sci 1980; 58: 30P.

${ }^{24}$ Walker V, Taylor WH. Pepsin 1 secretion in peptic ulcer and in stress. (Abstract) Clin Sci Mol Med 1976; 51 : 14.

${ }^{25}$ Walker V, Taylor WH. Pepsin inhibition in vivo and the therapeutic action of carbenoxolone. In: Avery Jones F, Parke DV, eds. Fourth Symposium on Carbenoxolone. London: Butterworths, 1975; 55-69. 